\title{
Analysis of Time Course and Dose Effect From Metformin on Body Mass Index in Children and Adolescents
}

\section{OPEN ACCESS}

Edited by:

Alfredo Vannacci,

University of Florence, Italy

Reviewed by: Michael Lloyd Christensen, University of Tennessee Health

Science Center (UTHSC),

United States

Kathleen Job,

The University of Utah, United States

${ }^{*}$ Correspondence:

Dong-Dong Wang

13852029591@163.com

Su-Mei He

hehe8204@163.com

Xiao Chen

chenxiao112733@163.com

${ }^{\dagger}$ These authors have contributed equally to this work

Specialty section:

This article was submitted to Obstetric and Pediatric Pharmacology, a section of the journal

Frontiers in Pharmacology

Received: 29 September 2020

Accepted: 01 March 2021

Published: 26 April 2021

Citation:

Wang D-D, Mao Y-Z, He S-M and Chen X (2021) Analysis of Time Course and Dose Effect From Metformin on

Body Mass Index in Children and Adolescents.

Front. Pharmacol. 12:611480. doi: 10.3389/fphar.2021.611480

\author{
Dong-Dong Wang ${ }^{1 * t}$, Yi-Zhen $\mathrm{Mao}^{2 \dagger}$, Su-Mei He ${ }^{3 *}$ and Xiao Chen ${ }^{1,4,5 *}$
}

${ }^{1}$ Jiangsu Key Laboratory of New Drug Research and Clinical Pharmacy, School of Pharmacy, Xuzhou Medical University, Xuzhou, China, ${ }^{2}$ Department of Endocrinology, Xuzhou Central Hospital, Xuzhou, China, ${ }^{3}$ Department of Pharmacy, The Affiliated Suzhou Science and Technology Town Hospital of Nanjing Medical University, Suzhou, China, ${ }^{4}$ Department of Pharmacy, The People's Hospital of Jiangyin, Jiangyin, China, ${ }^{5}$ Department of Pharmacy, Children's Hospital of Fudan University, Shanghai, China

The purpose of this study was to analyze the time course and dose effect from metformin on body mass index (BMI) in children and adolescents by model-based meta-analysis (MBMA). Searching randomized controlled trial (RCT) studies of metformin on BMl in children and adolescents. The change rates of BMl from baseline values were used as indicator of evaluating metformin efficacy. A total of 18 RCT studies, 1,228 children and adolescents, were included for analysis, including patients with obesity, patients with type 1 diabetes mellitus, patients with nonalcoholic fatty liver, and patients with precocity. In order to achieve better effect of metformin on BMI in children and adolescents, the present study recommended that for patients with obesity, 1,000 mg/day metformin was required for at least 15.2 weeks and 60.8 weeks to achieve the plateau of metformin effect; for patients with type 1 diabetes mellitus, $1,000 \mathrm{mg} /$ day metformin was required for at least 25.2 weeks and 100.8 weeks to achieve the plateau of metformin effect; for patients with nonalcoholic fatty liver, $1,000 \mathrm{mg} /$ day metformin was required for at least 6.57 weeks and 26.28 weeks to achieve the plateau of metformin effect; for patients with precocity, $425 \mathrm{mg} /$ day metformin was required for at least 12.4 weeks and 49.6 weeks to achieve the plateau of metformin effect. It was the first time to analyze the time course and dose effect from metformin on BMl and to recommend dosage and duration of treatment for metformin in children and adolescents with different disease types.

Keywords: time course, dose effect, metformin, body mass index, children and adolescents

\section{INTRODUCTION}

Metformin was widely used in the control of weight in different diseases of children and adolescents (Kendall et al., 2013; Pastor-Villaescusa et al., 2017). For example, patients with obesity (Atabek and Pirgon, 2008; Burgert et al., 2008; Love-Osborne et al., 2008; Clarson et al., 2009; Wilson et al., 2010; Yanovski et al., 2011; Gomez-Diaz et al., 2012; Kendall et al., 2013; van der Aa et al., 2016; GaribayNieto et al., 2017; Pastor-Villaescusa et al., 2017), patients with type 1 diabetes mellitus (Codner et al., 2013; Nadeau et al., 2015; Nwosu et al., 2015), patients with nonalcoholic fatty liver (Nadeau et al., 2009; Lavine et al., 2011), and patients with precocity (Ibanez et al., 2006a; Ibanez et al., 2006b). Metformin controlled weight mainly through decreasing caloric intake, including direct and indirect impacts on appetite regulation from the gastrointestinal side effects (Yerevanian and Soukas, 2019). In addition, metformin increased the peptide hormone growth/differentiation factor 15 (GDF15) 
circulating levels, lowering food intake and reducing body weight by means of the brain-stem-restricted receptor (Coll et al., 2020). However, the weight control of patients with metformin was offlabel, lacking clinical dosage and duration of treatment recommendation. Especially, the time course and dose effect of metformin on body mass index (BMI) in children and adolescents with different disease types were unclear.

Model-based meta-analysis (MBMA) was a new quantitative pharmacological tool and could quantify dose course and time effect of drug (Mould, 2012; Wu et al., 2017). In particular, it could implement accurate pharmacodynamic comparison from the same drug in different disease types (Dong et al., 2018) and realize clinical drug dosage and duration of treatment recommendation (Chen et al., 2020a; Chen et al., 2020b; Cheng et al., 2020). The purpose of this study was to analyze the time course and dose effect from metformin on BMI using MBMA method and to recommend dosage and duration of treatment for metformin in children and adolescents with different disease types.

\section{METHODS}

\section{Literature Search and Data Extraction}

We retrieved the Pubmed database (https://pubmed.ncbi.nlm. nih.gov/) with the deadline of September 2020. Only English publications were searched. Inclusion criteria included: 1) children and adolescents, 2) metformin treatment, 3) randomized controlled trial (RCT), 4) placebo controlled trial, and 5) with BMI information. Disease type, source, grouping, metformin dosage and duration of treatment, BMI, number of patient, and age were extracted from the above included studies. History and search details were shown in the Supporting Material (Supplementary Table S1). In order to eliminate the potential baseline effect, metformin efficacy (E) was evaluated using BMI change rate from baseline values in the present research. Eq. 1 was as follows:

$$
\mathrm{E} \%=\frac{\mathrm{E}_{\mathrm{t}}-\mathrm{E}_{\mathrm{b}}}{\mathrm{E}_{\mathrm{b}}} \times 100 \%
$$

$\mathrm{E}_{t}$, the value of BMI at time $t$; $\mathrm{E}_{\mathrm{b}}$, the value of BMI at baseline.

\section{Model Establishment}

In order to get actual drug effect on BMI from metformin, the placebo effect should be deducted from the metformin group. In addition, $\mathrm{E}_{\max }$ models were used to assess the effect of metformin on BMI in children and adolescents with different disease types because the effect on BMI from metformin varied with time and reached a plateau. Eqs. 2, 3 were as follows:

$$
\begin{aligned}
& E_{m, i, j}=E_{g, i, j}-E_{p, i, j}, \\
& E_{m, i, j}=\frac{E_{m a x, i, j} \times \text { Time }}{E T_{50, i, j}+\text { Time }}+\frac{\varepsilon_{i, j}}{\sqrt{\frac{N_{i, j}}{100}}},
\end{aligned}
$$

$E_{g, i, j}$, the sum effect on BMI from metformin, including actual metformin effect and placebo effect; $\mathrm{E}_{\mathrm{m}, \mathrm{i}, \mathrm{j}}$, the actual metformin

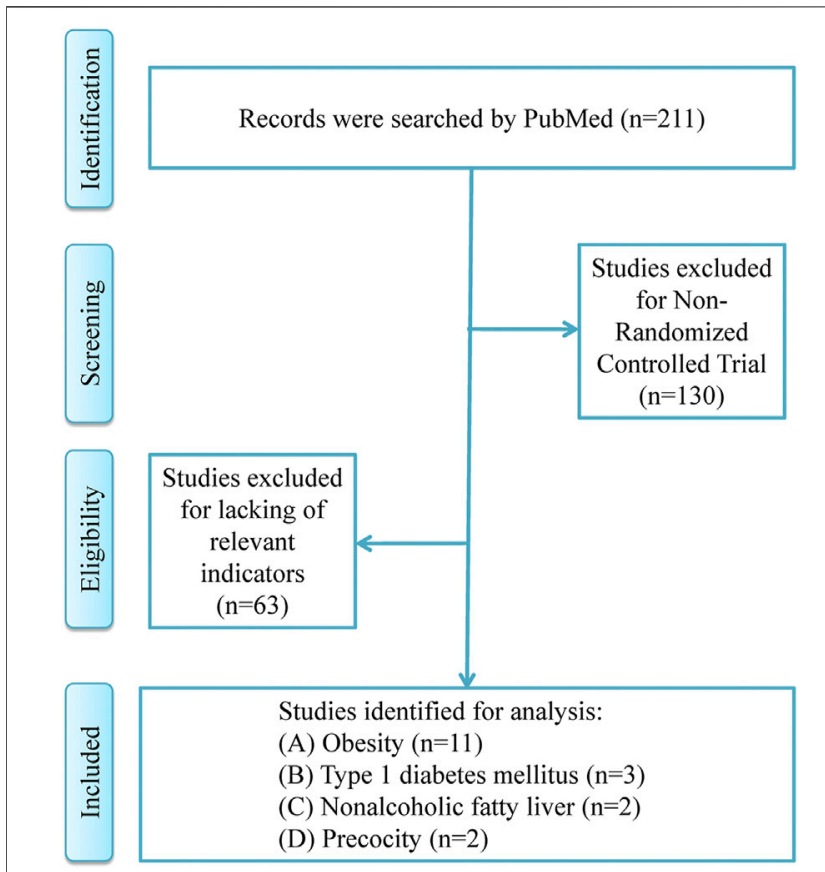

FIGURE 1 | Strategy for literature search.

effect on BMI; $E_{p}, i, j$, the placebo effect on BMI. i, different studies; $j$, time point of every study. $E_{\max }$, the maximal effect of metformin on $\mathrm{BMI} ; \mathrm{ET}_{50}$, the treatment duration to reach half of the maximal effect of metformin on BMI; $\mathcal{E}_{\mathrm{i}, \mathrm{j}}$, the residual error of study $i$ with $j$ time; $N_{i, j}$, the sample size in study $i$ with time point j. $\varepsilon_{\mathrm{i}, \mathrm{j}}$ was weighted by sample size, assumed to be normally distributed, with a mean of 0 and variance of $\sigma^{2} /\left(\mathrm{N}_{\mathrm{i}, \mathrm{j}} / 100\right)$.

Additive error or exponential error models were used to describe the inter-study variability. Eqs. 4-7 were as follows:

$$
\begin{aligned}
& E_{\max , \mathrm{i}, \mathrm{j}}=\mathrm{E}_{\max }+\eta_{1, \mathrm{i}}, \\
& \mathrm{ET}_{50, \mathrm{i}, \mathrm{j}}=\mathrm{ET}_{50}+\eta_{2, \mathrm{i}}, \\
& \mathrm{E}_{\max , \mathrm{i}, \mathrm{j}}=\mathrm{E}_{\max } \times \exp \left(\eta_{1, \mathrm{i}}\right), \\
& \mathrm{ET}_{50, \mathrm{i}, \mathrm{j}}=\mathrm{ET}_{50} \times \exp \left(\eta_{2, \mathrm{i}}\right),
\end{aligned}
$$

$\eta_{1, \mathrm{i}}$ and $\eta_{2, \mathrm{i}}$ were the inter-study variabilities; when available, they would be added into $\mathrm{E}_{\max }$ and $\mathrm{ET}_{50}$, respectively. $\eta_{1, \mathrm{i}}$ and $\eta_{2, \mathrm{i}}$ were assumed to normally distributed, with a mean of 0 and variance of $\omega_{1, \mathrm{i}}^{2}$ and $\omega_{2, \mathrm{i}}^{2}$, respectively.

When building the covariates models, categorical covariates and continuous covariates were evaluated by Eqs. 8-10:

$$
\begin{aligned}
& \mathrm{P}_{\mathrm{p}}=\mathrm{P}_{\mathrm{T}}+\mathrm{COV} \times \theta_{\mathrm{c}}, \\
& \mathrm{P}_{\mathrm{p}}=\mathrm{P}_{\mathrm{T}}+\left(\mathrm{COV}-\mathrm{COV}_{\mathrm{m}}\right) \times \theta_{\mathrm{c}}, \\
& \mathrm{P}_{\mathrm{p}}=\mathrm{P}_{\mathrm{T}} \times\left(\mathrm{COV} / \mathrm{COV}_{\mathrm{m}}\right)^{\theta_{\mathrm{c}}},
\end{aligned}
$$

$\mathrm{COV}$, covariate; $\mathrm{P}_{\mathrm{p}}$, the parameter for a patient with a covariate value of $\mathrm{COV}$; $\mathrm{P}_{\mathrm{T}}$, the typical value of the parameter; $\mathrm{COV}_{\mathrm{m}}$, the median value of covariable in the population. $\theta_{c}$, a correction coefficient of the covariate to the model parameter. 
TABLE 1 | Studies identified for analysis.

\begin{tabular}{|c|c|c|c|c|c|c|c|c|}
\hline Disease & Study & Country & Group & $\begin{array}{l}\text { Dosages } \\
\text { (g/day) }\end{array}$ & $\begin{array}{c}\text { Duration } \\
\text { of } \\
\text { treatment }\end{array}$ & $\begin{array}{c}\text { Body } \\
\text { mass } \\
\text { index } \\
\left(\mathbf{k g} / \mathrm{m}^{2}\right)\end{array}$ & $\begin{array}{l}\text { Number } \\
\text { of people }\end{array}$ & Age (years) \\
\hline \multirow[t]{4}{*}{ Obesity } & \multirow[t]{4}{*}{$\begin{array}{l}\text { Pastor-Villaescusa et al. } \\
(2017)\end{array}$} & \multirow[t]{4}{*}{ Spain } & $\begin{array}{l}\text { Metformin } \\
\text { (prepubertal) }\end{array}$ & 1 & 6 months & 28.2 & 40 & $6.8-15.3$ \\
\hline & & & Placebo (prepubertal) & & 6 months & 29.2 & 40 & $6.8-15.3$ \\
\hline & & & Metformin (pubertal) & 1 & 6 months & 29.4 & 40 & $6.8-15.3$ \\
\hline & & & Placebo (pubertal) & & 6 months & 30.6 & 40 & $6.8-15.3$ \\
\hline \multirow[t]{2}{*}{ Obesity } & \multirow[t]{2}{*}{ Garibay-Nieto et al. (2017) } & \multirow[t]{2}{*}{ Mexico } & Metformin & 1 & 4 months & 28.54 & 14 & $11.43 \pm 2.1$ \\
\hline & & & Placebo & & 4 months & 28.79 & 17 & $12.59 \pm 2.62$ \\
\hline \multirow[t]{2}{*}{ Obesity } & \multirow[t]{2}{*}{ van der Aa et al. (2016) } & \multirow[t]{2}{*}{ Netherlands } & Metformin & 2 & 18 months & 29.8 & 23 & $12.6-15.3$ \\
\hline & & & Placebo & & 18 months & 30.5 & 19 & $11.3-14.0$ \\
\hline \multirow[t]{2}{*}{ Obesity } & \multirow[t]{2}{*}{ Kendall et al. (2013) } & \multirow[t]{2}{*}{ United Kingdom } & Metformin & 1.5 & 6 months & 37.1 & 74 & $13.68 \pm 2.3$ \\
\hline & & & Placebo & & 6 months & 35.95 & 77 & $13.64 \pm 2.2$ \\
\hline \multirow[t]{2}{*}{ Obesity } & \multirow[t]{2}{*}{ Gómez-Díaz et al., (2012) } & \multirow[t]{2}{*}{ Mexico } & Metformin & 1.7 & 12 weeks & 31.1 & 28 & 7.0-16.4 \\
\hline & & & Placebo & & 12 weeks & 27.1 & 24 & $4.4-15.91$ \\
\hline \multirow[t]{2}{*}{ Obesity } & \multirow[t]{2}{*}{ Yanovski et al. (2011) } & \multirow[t]{2}{*}{ United States } & Metformin & 2 & 12 months & 34.2 & 53 & $10.1 \pm 1.6$ \\
\hline & & & Placebo & & 12 months & 34.6 & 47 & $10.4 \pm 1.4$ \\
\hline \multirow[t]{2}{*}{ Obesity } & \multirow[t]{2}{*}{ Wilson et al. (2010) } & \multirow[t]{2}{*}{ United States } & Metformin & 2 & 52 weeks & 35.9 & 39 & $14.8 \pm 1.3$ \\
\hline & & & Placebo & & 52 weeks & 35.9 & 38 & $15.0 \pm 1.5$ \\
\hline \multirow[t]{2}{*}{ Obesity } & \multirow[t]{2}{*}{ Clarson et al. (2009) } & \multirow[t]{2}{*}{ Canada } & Metformin & 1.5 & 6 months & 36.4 & 11 & $10.1-16.1$ \\
\hline & & & Placebo & & 6 months & 33.9 & 14 & $10.1-16.1$ \\
\hline \multirow[t]{2}{*}{ Obesity } & Burgert et al. (2008) & United States & Metformin & 1.5 & 4 months & 41 & 15 & $15 \pm 2$ \\
\hline & & & Placebo & & 4 months & 40 & 13 & $15 \pm 1$ \\
\hline Obesity & Atabek and Pirgon(2008) & Turkey & Metformin & 1 & 6 months & 28.5 & 90 & $11.83 \pm 2.8$ \\
\hline & & & Placebo & & 6 months & 28 & 30 & $11.6 \pm 2.7$ \\
\hline Obesity & Love-Osborne et al. & United States & Metformin & 1.7 & 6 months & 39.4 & 60 & $15.5 \pm 1.7$ \\
\hline & (2008) & & Placebo & & 6 months & 39.3 & 25 & $14.2 \pm 4.6$ \\
\hline Type 1 diabetes & Nwosu et al. (2015) & United States & Metformin & 1 & 9 months & 28 & 15 & $15.0 \pm 2.5$ \\
\hline mellitus & & & Placebo & & 9 months & 27.7 & 13 & $14.5 \pm 3.1$ \\
\hline Type 1 diabetes & Nadeau et al. (2015) & United States & Metformin & 1 & 6 months & 23.5 & 40 & $15.9 \pm 1.7$ \\
\hline mellitus & & & Placebo & & 6 months & 24.3 & 40 & $16.0 \pm 1.6$ \\
\hline Type 1 diabetes & Codner et al. (2013) & Chile & Metformin & 1.7 & 9 months & 23.7 & 13 & $17.7 \pm 1.6$ \\
\hline mellitus & & & Placebo & & 9 months & 26.2 & 11 & $16.7 \pm 1.7$ \\
\hline Nonalcoholic fatty liver & Lavine et al. (2011) & United States & Metformin & 1 & 96 weeks & 34 & 57 & $13.1 \pm 2.4$ \\
\hline & & & Placebo & & 96 weeks & 33 & 58 & $12.9 \pm 2.6$ \\
\hline Nonalcoholic fatty liver & Nadeau et al. (2009) & United States & Metformin & 1.7 & 6 months & 39.6 & 37 & $12-18$ \\
\hline & & & Placebo & & 6 months & 40.2 & 13 & $12-18$ \\
\hline Precocity & Ibáñez et al. (2006a) & Spain & Metformin & 0.425 & 24 months & 18.7 & 19 & $7.9 \pm 0.2$ \\
\hline & & & Placebo & & 24 months & 18.1 & 19 & $8.0 \pm 0.2$ \\
\hline Precocity & Ibáñez et al. (2006b) & Spain & Metformin & 0.85 & 36 months & 21 & 10 & $9.0 \pm 0.1$ \\
\hline & & & Placebo & & 36 months & 20.2 & 12 & $9.1 \pm 0.1$ \\
\hline
\end{tabular}

The nonlinear mixed effect modeling (NONMEM, edition 7, ICON Development Solutions, Ellicott City, MD, United States) was used to build models. After a basic model was built, potential covariates were considered to add into $\mathrm{E}_{\max }$. Objective function value $(\mathrm{OFV})$ changes were as the covariate inclusion criteria. The decrease from OFV was greater than $3.84\left(\chi^{2}, \alpha=0.05\right.$, d.f. $\left.=1\right)$, which was considered sufficient for inclusion; the increase of OFV was greater than $6.63\left(\chi^{2}, \alpha=0.01\right.$, d.f. $\left.=1\right)$, which was considered sufficient for significance in the final model.

\section{Model Validation and Prediction}

The final model accuracy was evaluated by visual inspection of routine diagnostic plots (individual predictions vs. observations). Prediction-corrected visual predictive check plots were used to assess the predictive performance of final models. The efficacy prediction from metformin on BMI in children and adolescents with different disease types was simulated by Monte Carlo method.

\section{RESULTS}

\section{Included Studies}

The process of literature search and details of included studies were shown in Figure 1; Table 1, respectively. A total of 18 RCT studies, 1,228 children and adolescents, were included for analysis, in which 11 studies for patients with obesity (Atabek and Pirgon, 2008; Burgert et al., 2008; Love-Osborne et al., 2008; Clarson et al., 2009; Wilson et al., 2010; Yanovski et al., 2011; Gomez-Diaz et al., 2012; Kendall et al., 2013; van der Aa et al., 2016; Garibay-Nieto et al., 2017; Pastor-Villaescusa et al., 2017), 3 studies for patients with type 1 diabetes mellitus (Codner et al., 
TABLE 2 | Parameter estimates of final models.

\begin{tabular}{llc}
\hline Model & \multicolumn{1}{c}{ Parameter } & Estimate \\
\hline (A) & $E_{\max }, \%$ & -10 \\
& $E T_{50}$, week & 15.2 \\
& $\omega_{E \max }$ & 6.025 \\
& $\omega_{E T 50}$ & - \\
& $\varepsilon$ & 0.27 \\
(C) & $E_{\max }, \%$ & -4.7 \\
& $E T_{50}$, week & 6.57 \\
& $\omega_{E \max }$ & 2.062 \\
& $\omega_{E T 50}$ & - \\
& $\varepsilon$ & 0.01 \\
(B) & $E_{\max }, \%$ & -4.31 \\
& $E T_{50}$, week & 25.2 \\
& $\omega_{E \max }$ & 1.995 \\
& $\omega_{E T 50}$ & - \\
& $\varepsilon$ & 2.296 \\
(D) & $E_{\max }, \%$ & -9.41 \\
& $E_{50}$, week & 12.4 \\
& $\omega_{E \max }$ & 0.742 \\
& $\omega_{E T 50}$ & - \\
& $\varepsilon$ & 0.01 \\
& &
\end{tabular}

2013; Nadeau et al., 2015; Nwosu et al., 2015), 2 studies for patients with nonalcoholic fatty liver (Nadeau et al., 2009; Lavine et al., 2011), and 2 studies for patients with precocity (Ibanez et al., 2006a; Ibanez et al., 2006b). In addition, in the included studies, the dosage ranges of metformin in patients with obesity were $1,000 \mathrm{mg} /$ day-2,000 $\mathrm{mg} /$ day, in patients with type 1 diabetes mellitus were $1,000 \mathrm{mg} /$ day- $1,700 \mathrm{mg} /$ day, in patients with nonalcoholic fatty liver were $1,000 \mathrm{mg} / \mathrm{day}-1,700 \mathrm{mg} / \mathrm{day}$, and in patients with precocity were $425 \mathrm{mg} /$ day $-850 \mathrm{mg} /$ day, respectively.

\section{Modeling}

The actual drug effect on BMI from metformin in children and adolescents with different disease types was shown in Table 2; the $E_{\max }$ of metformin on BMI in patients with obesity, patients with type 1 diabetes mellitus, patients with nonalcoholic fatty liver, and patients with precocity were $-10,-4.31,-4.7$, and $-9.41 \%$, respectively. The $\mathrm{ET}_{50}$ of metformin on BMI in patients with obesity, patients with type 1 diabetes mellitus, patients with nonalcoholic fatty liver, and patients with precocity were 15.2, 25.2, 6.57, and 12.4 weeks, respectively. In addition, no covariate (in particular dosage) was incorporated into the $\mathrm{E}_{\max }$ models, showing there was no significant dose dependence from metformin efficacy on BMI in children and adolescents with different disease types from the current included studies.

The $\mathrm{E}_{\max }$ models of metformin on BMI in patients with obesity, patients with type 1 diabetes mellitus, patients with nonalcoholic fatty liver, and patients with precocity were shown in Eqs. 11-14, respectively:

$$
\begin{gathered}
\mathrm{E}=\frac{-10 \% \times \text { Time }}{15.2+\text { Time }}, \\
\mathrm{E}=\frac{-4.31 \% \times \text { Time }}{25.2+\text { Time }},
\end{gathered}
$$

$$
\begin{aligned}
& \mathrm{E}=\frac{-4.7 \% \times \text { Time }}{6.57+\text { Time }} \\
& \mathrm{E}=\frac{-9.41 \% \times \text { Time }}{12.4+\text { Time }}
\end{aligned}
$$

E, efficacy of metformin on BMI; Time, metformin treatment duration.

\section{Validation}

The visual inspection of routine diagnostic plots was shown in Figure 2. Figures 2A-D were used to assess the final models of metformin on BMI in patients with obesity, patients with type 1 diabetes mellitus, patients with nonalcoholic fatty liver, and patients with precocity, respectively. As we could see, there were good linear relationships between individual predictions and observations, meaning the good fitting of the final models.

The visual predictive check plots were shown in Figure 3. Figures 3A-D, were used to evaluate the predictive performance of final models from metformin on BMI in patients with obesity, patients with type 1 diabetes mellitus, patients with nonalcoholic fatty liver, and patients with precocity, respectively, in which most observed data were included in the $95 \%$ prediction intervals produced by simulation data, showing the predictive power of the final models.

\section{Prediction}

The trends of efficacy of metformin on BMI in patients with obesity, patients with type 1 diabetes mellitus, patients with nonalcoholic fatty liver, and patients with precocity were shown in Figures $\mathbf{4 A - D}$, respectively. In patients with obesity, the efficacy of metformin on BMI at 5.1 weeks was $25 \%$ of the $\mathrm{E}_{\max }$, at 15.2 weeks was $50 \%$ of the $\mathrm{E}_{\max }$, at 45.6 weeks was $75 \%$ of the $\mathrm{E}_{\max }$, and at 60.8 weeks was $80 \%$ of the $E_{\text {max }}$. In patients with type 1 diabetes mellitus, the efficacy of metformin on BMI at 8.4 weeks was $25 \%$ of the $\mathrm{E}_{\max }$, at 25.2 weeks was $50 \%$ of the $\mathrm{E}_{\max }$, at 75.6 weeks was $75 \%$ of the $\mathrm{E}_{\max }$, and at 100.8 weeks was $80 \%$ of the $\mathrm{E}_{\max }$. In patients with nonalcoholic fatty liver, the efficacy of metformin on BMI at 2.19 weeks was $25 \%$ of the $\mathrm{E}_{\max }$, at 6.57 weeks was $50 \%$ of the $\mathrm{E}_{\max }$, at 19.71 weeks was $75 \%$ of the $\mathrm{E}_{\max }$, and at 26.28 weeks was $80 \%$ of the $\mathrm{E}_{\max }$. In patients with precocity, the efficacy of metformin on $\mathrm{BMI}$ at 4.2 weeks was $25 \%$ of the $\mathrm{E}_{\max }$, at 12.4 weeks was $50 \%$ of the $\mathrm{E}_{\max }$, at 37.2 weeks was $75 \%$ of the $\mathrm{E}_{\max }$, and at 49.6 weeks was $80 \%$ of the $\mathrm{E}_{\max }$.

\section{DISSCUSION}

Metformin was increasingly used to control weight in children and adolescents, such as patients with obesity (Atabek and Pirgon, 2008; Burgert et al., 2008; Love-Osborne et al., 2008; Clarson et al., 2009; Wilson et al., 2010; Yanovski et al., 2011; Gomez-Diaz et al., 2012; Kendall et al., 2013; van der Aa et al., 2016; Garibay-Nieto et al., 2017; Pastor-Villaescusa et al., 2017), patients with type 1 diabetes mellitus (Codner et al., 2013; Nadeau et al., 2015; Nwosu et al., 2015), patients with nonalcoholic fatty 


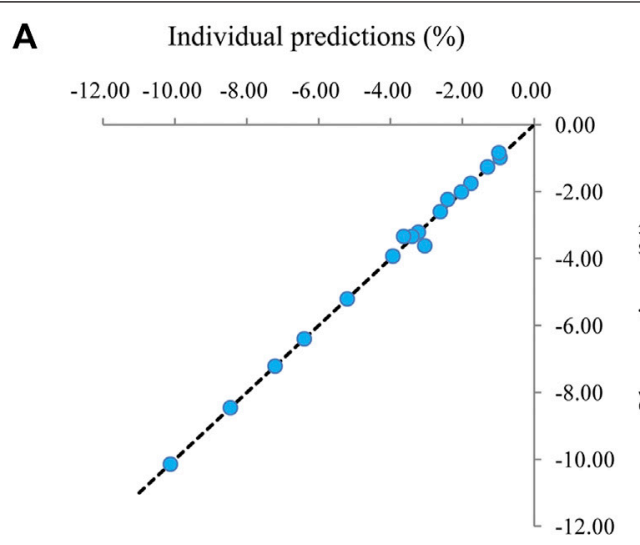

C Individual predictions (\%)

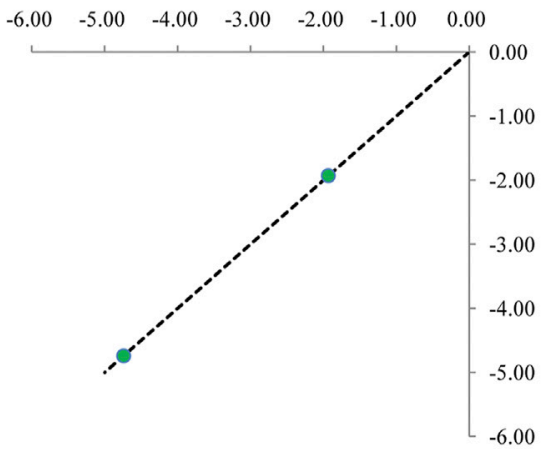

B Individual predictions (\%)

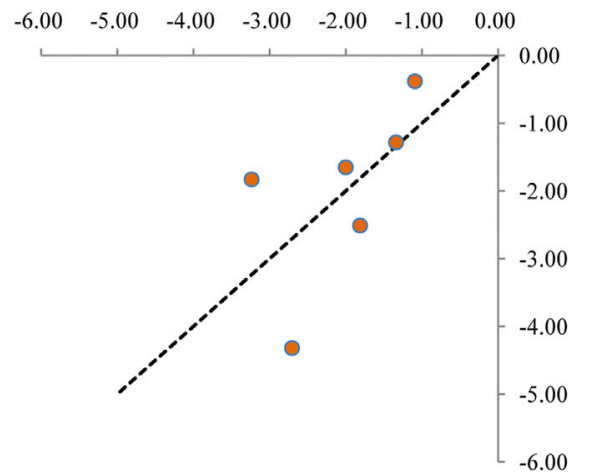

0
0
0
0
0
0
0
0
0
0

D Individual predictions (\%)

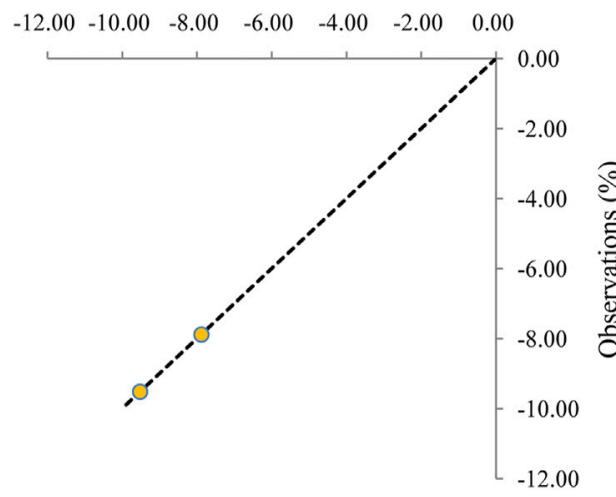

FIGURE 2 | Visual inspection of routine diagnostic plots. (A) Patients with obesity, (B) patients with type 1 diabetes mellitus, (C) patients with nonalcoholic fatty liver., (D) patients with precocity.

liver (Nadeau et al., 2009; Lavine et al., 2011), and patients with precocity (Ibanez et al., 2006a; Ibanez et al., 2006b). However, lacking dosage and duration of treatment recommendation made it difficult to promote metformin usage in children and adolescents with different disease types for control of weight. The present study was to analyze the time course and dose effect from metformin on BMI using the MBMA method and to recommend dosage and duration of treatment from metformin in children and adolescents with different disease types.

In the present study, the $\mathrm{E}_{\max }$ of metformin on BMI in patients with obesity, patients with type 1 diabetes mellitus, patients with nonalcoholic fatty liver, and patients with precocity were $-10,-4.31,-4.7$, and -9.41 , respectively. The $\mathrm{ET}_{50}$ of metformin on BMI in patients with obesity, patients with type 1 diabetes mellitus, patients with nonalcoholic fatty liver, and patients with precocity were 15.2, 25.2, 6.57, and 12.4 weeks, respectively. Of course, the present study was not isolated. In the previous study from Chen et al, the change rate of weight from baseline was selected as the efficacy indicator, and the ET50 in patients with obesity was 15.1 weeks (Chen et al., 2020b), which had the similar $\mathrm{ET}_{50}$ value with the present study. However, the population in the previous study was not entirely children and adolescents, and the number of previously included studies in Chen et al. (2020b) was also lower than that of the current study.

In addition, in our present study, no covariate (in particular, metformin dosage) was incorporated into the $\mathrm{E}_{\max }$ models, showing there was no significant dose dependence from metformin efficacy on BMI in children and adolescents with different disease types from the current included studies. In other words, we could recommend the lower limits of the metformin dose ranges on the basis of the current included studies for different disease types. Further, to achieve the $80 \%$ efficacy of $E_{\max }$, which was called plateau, metformin treatment duration were $60.8,100.8,26.28$, and 49.6 weeks in patients with obesity, patients with type 1 diabetes mellitus, patients with nonalcoholic fatty liver, and patients with precocity, respectively. For type 1 diabetes mellitus, no study went beyond 9 months, yet estimates for metformin effect were being extrapolated to 100.8 weeks, which would be further verified in the future research. Furthermore, countries were 
A

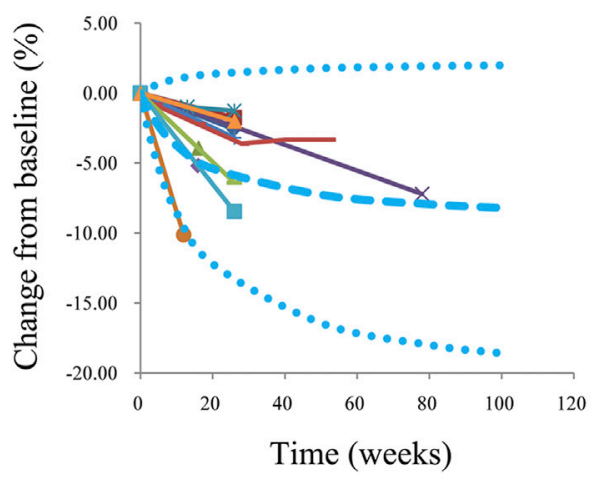

C

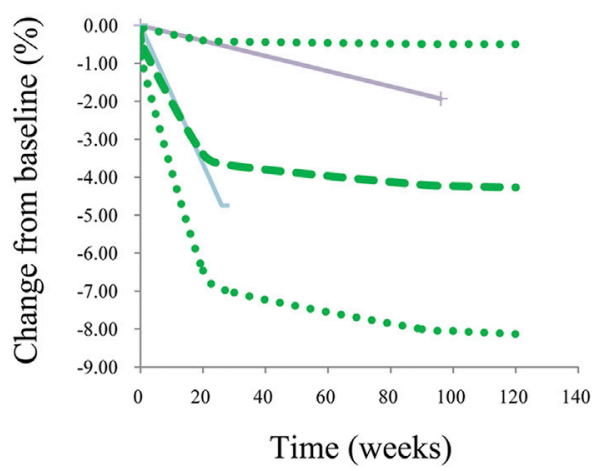

B

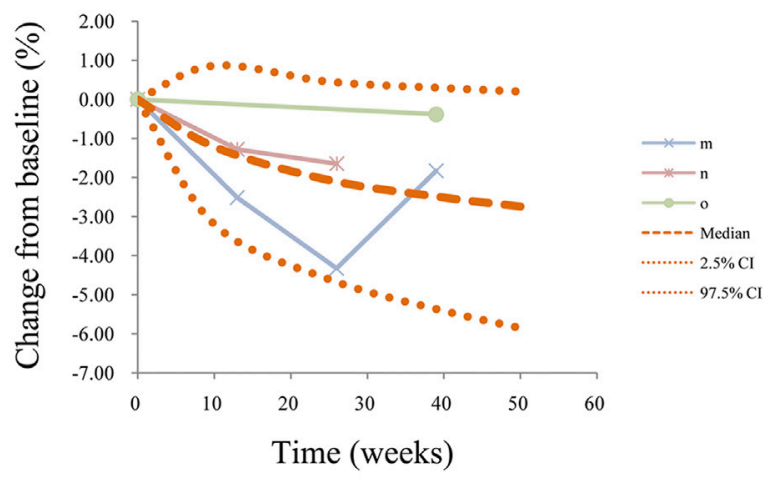

D

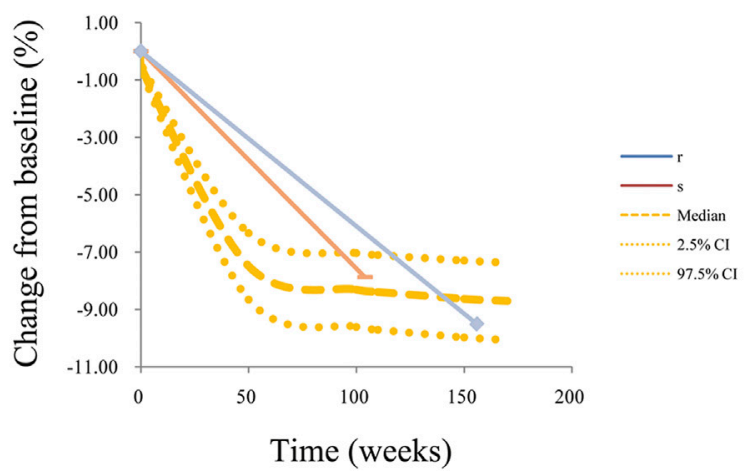

FIGURE 3 | Prediction-corrected visual predictive check plots. (A) patients with obesity, (B) patients with type 1 diabetes mellitus, (C) patients with nonalcoholic fatty liver, and (D) patients with precocity. Median, 2.5\% Cl, and 97.5\% Cl were simulated by Monte Carlo ( $\mathrm{n}=1,000)$; Cl; a, Pastor-Villaescusa et al. (2017); b, PastorVillaescusa et al. (2017); c, Garibay-Nieto et al. (2017); d, van der Aa et al. (2016); e, Kendall et al. (2013); f, Gómez-Díaz et al. (2012); g, Yanovski et al. (2011); h, Wilson et al. (2010); i, Clarson et al. (2009); j, Burgert et al. (2008); k, Atabek and Pirgon (2008); I, Love-Osborne et al. (2008); m, Nwosu et al. (2015); n, Nadeau et al. (2015); o, Codner et al. (2013); p, Lavine et al. (2011); q, Nadeau et al. (2009); r, Ibáñez et al. (2006a); s, Ibáñez et al. (2006b).

also analyzed in this study as a categorical covariable, however, were not included in the $\mathrm{E}_{\max }$ models, revealing there was no significant country dependence from metformin efficacy on BMI in children and adolescents with different disease types from the current included studies.

The present study recommended that for patients with obesity, $1,000 \mathrm{mg} /$ day metformin was required for at least 15.2 weeks, and 60.8 weeks to achieve the plateau of metformin effect. However, in the study from $\mathrm{Pu}$ et al (2020), effects of metformin in obesity treatment, they found high dose metformin $(>1,500 \mathrm{mg} / \mathrm{d})$ was more effective in reducing BMI, yet more than half of their studies were on adults. In our study, only children and adolescents were involved. That was to say, the composition of the population would have a certain impact on the choice of dosage. The optimal dose for children and adolescents was lower than that for adults. In addition, for patients with type 1 diabetes mellitus, $1,000 \mathrm{mg} /$ day metformin was required for at least 25.2 weeks and 100.8 weeks to achieve the plateau of metformin effect. For patients with nonalcoholic fatty liver, $1,000 \mathrm{mg} /$ day metformin was required for at least 6.57 weeks and 26.28 weeks to achieve the plateau of metformin effect. For patients with precocity, $425 \mathrm{mg} /$ day metformin was required for at least 12.4 weeks and 49.6 weeks to achieve the plateau of metformin effect.

However, there were limited data for all the various dosages studied across the timeframe; for nonalcoholic fatty liver and precocity, only 2 studies were identified. In addition, there were almost no studies on children younger than 4 years old included in the present study. In terms of geographical scope, the Asian countries and populations involved in this study were small. Therefore, the results of this study would be further verified in the following clinical studies or trials.

\section{CONCLUSION}

It was the first time to analyze the time course and dose effect from metformin on BMI in children and adolescents and meanwhile to recommend dosage and duration of treatment for metformin in patients with obesity, patients with type 1 


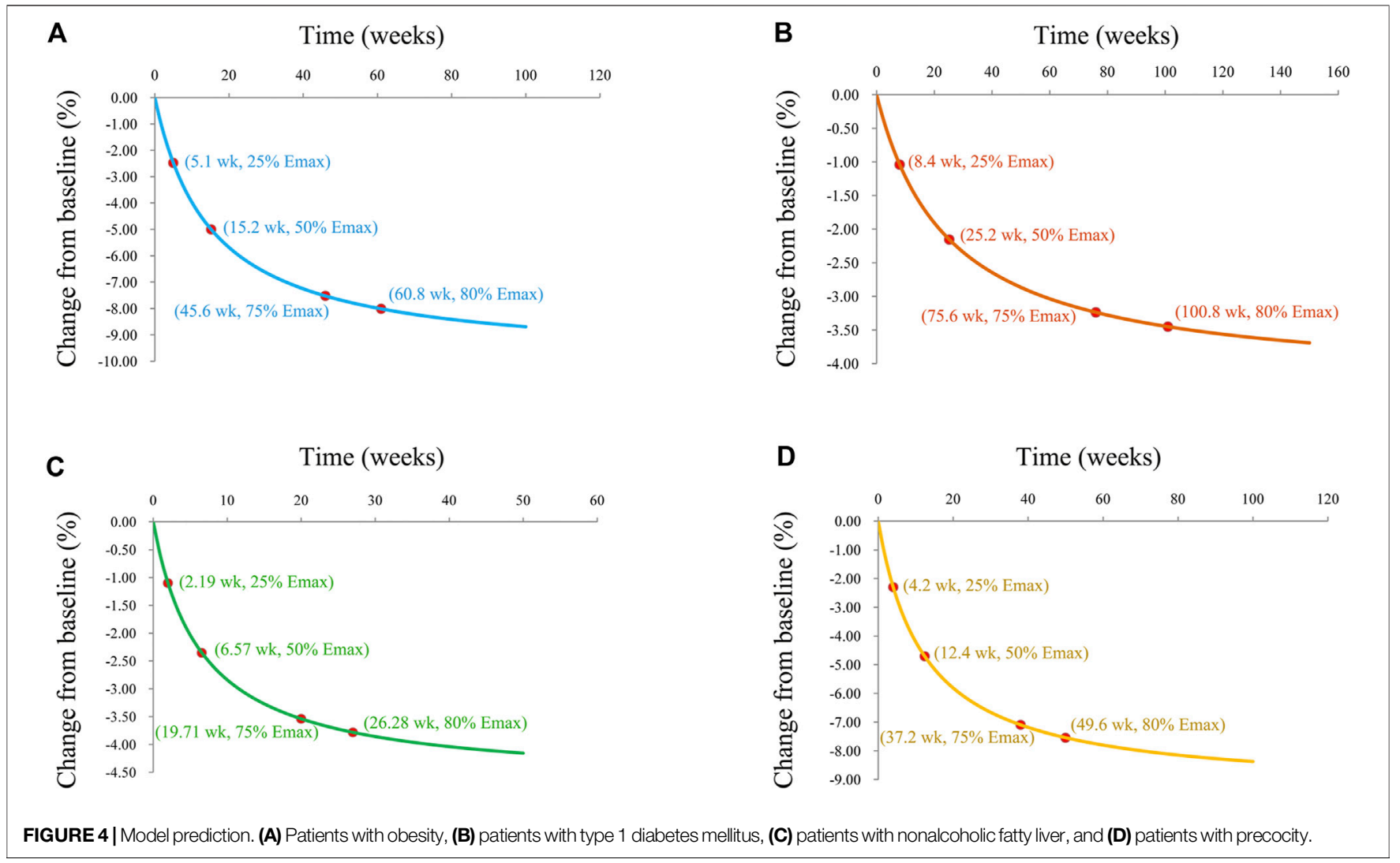

diabetes mellitus, patients with nonalcoholic fatty liver, and patients with precocity, respectively. The recommendations would be validated in future clinical studies or trials.

\section{DATA AVAILABILITY STATEMENT}

The original contributions presented in the study are included in the article/Supplementary Material, and further inquiries can be directed to the corresponding authors.

\section{AUTHOR CONTRIBUTIONS}

D-DW, S-MH, and XC conceived and designed the study. D-DW, Y-ZM, S-MH, and XC collected the data. D-DW and $\mathrm{XC}$ built the model and evaluated the data. D-DW, Y-ZM, and $\mathrm{S}-\mathrm{MH}$ wrote the manuscript. XC reviewed and edited the manuscript. All authors read and approved the manuscript.

\section{REFERENCES}

Atabek, M. E., and Pirgon, O. (2008). Use of metformin in obese adolescents with hyperinsulinemia: a 6-month, randomized, double-blind, placebo-controlled clinical trial. J. Pediatr. Endocrinol. Metab. 21 (4), 339-348. doi:10.1515/jpem.2008.21.4.339

Burgert, T. S., Duran, E. J., Goldberg-Gell, R., Dziura, J., Yeckel, C. W., Katz, S., et al. (2008). Short-term metabolic and cardiovascular effects of metformin in

\section{FUNDING}

This work was supported by the AOSAIKANG pharmaceutical foundation (No. A201826), The Young Medical Talents of Wuxi (No. QNRC020), Young Project of Wuxi Health and Family Planning Research (No. Q201706), and Wuxi science and technology development guidance plan (medical and health care) (No. CSZON1744). Suzhou Science \& Technology Town Hospital pre-research fund project (No. 2019Y01). Suzhou Science and Technology Development Plan Project (No.SYSD2019076). Jiangsu Pharmaceutical Society-Tianqing Hospital Pharmaceutical Fund Project (No. Q202024).

\section{SUPPLEMENTARY MATERIAL}

The Supplementary Material for this article can be found online at: https://www.frontiersin.org/articles/10.3389/fphar.2021.611480/ full\#supplementary-material.

markedly obese adolescents with normal glucose tolerance. Pediatr. Diabetes 9 (6), 567-576. doi:10.1111/j.1399-5448.2008.00434.x

Chen, X., Wang, D.-D., and Li, Z.-P. (2020b). Time course and dose effect of metformin on weight in patients with different disease states. Expert Rev. Clin. Pharmacol. 13, 1169. doi:10.1080/17512433.2020.1822164

Chen, X., Wang, D. D., and Li, Z. P. (2020a). Analysis of time course and dose effect of tacrolimus on proteinuria in lupus nephritis patients. J. Clin. Pharm. Ther. 46, 106. doi: $10.1111 /$ jcpt.13260 
Cheng, Q., Huang, J., Xu, L., Li, Y., Li, H., Shen, Y., et al. (2020). Analysis of timecourse, dose-effect, and influencing factors of antidepressants in the treatment of acute adult patients with major depression. Int. J. Neuropsychopharmacol. 23 (2), 76-87. doi:10.1093/ijnp/pyz062

Clarson, C. L., Mahmud, F. H., Baker, J. E., Clark, H. E., McKay, W. M., Schauteet, V. D., et al. (2009). Metformin in combination with structured lifestyle intervention improved body mass index in obese adolescents, but did not improve insulin resistance. Endocr 36 (1), 141-146. doi:10.1007/s12020-009-9196-9

Codner, E., Iñíguez, G., López, P., Mujica, V., Eyzaguirre, F. C., Asenjo, S., et al. (2013). Metformin for the treatment of hyperandrogenism in adolescents with type 1 diabetes mellitus. Horm. Res. Paediatr. 80 (5), 343-349. doi:10.1159/ 000355513

Coll, A. P., Chen, M., Taskar, P., Rimmington, D., Patel, S., Tadross, J. A., et al. (2020). GDF15 mediates the effects of metformin on body weight and energy balance. Nature 578 (7795), 444-448. doi:10.1038/s41586-019-1911-y

Dong, L., Xu, L., Li, Y., Lv, Y., Liu, H., Li, Y., et al. (2018). Model-based comparing efficacy of fluoxetine between elderly and non-elderly participants with major depressive disorder. J. Affective Disord. 229, 224-230. doi:10.1016/j.jad.2017.12.103

Garibay-Nieto, N., Queipo-García, G., Alvarez, F., Bustos, M., Villanueva, E., Ramírez, F., et al. (2017). Effects of conjugated linoleic acid and metformin on insulin sensitivity in obese children: randomized clinical trial. J. Clin. Endocrinol. Metab. 102 (1), 132-140. doi:10.1210/jc.2016-2701

Gómez-Díaz, R. A., Talavera, J. O., Pool, E. C., Ortiz-Navarrete, F. V., SolórzanoSantos, F., Mondragón-González, R., et al. (2012). Metformin decreases plasma resistin concentrations in pediatric patients with impaired glucose tolerance: a placebo-controlled randomized clinical trial. Metabolism 61 (9), 1247-1255. doi:10.1016/j.metabol.2012.02.003

Ibáñez, L., Ong, K., Valls, C., Marcos, M. V., Dunger, D. B., and de Zegher, F. (2006a). Metformin treatment to prevent early puberty in girls with precocious pubarche. J. Clin. Endocrinol. Metab. 91 (8), 2888-2891. doi:10.1210/jc.2006-0336

Ibáñez, L., Valls, C., Ong, K., Dunger, D. B., and de Zegher, F. (2006b). Metformin therapy during puberty delays menarche, prolongs pubertal growth, and augments adult height: a randomized study in low-birth-weight girls with early-normal onset of puberty. J. Clin. Endocrinol. Metab. 91 (6), 2068-2073. doi:10.1210/jc.2005-2329

Kendall, D., Vail, A., Amin, R., Barrett, T., Dimitri, P., Ivison, F., et al. (2013). Metformin in obese children and adolescents: the MOCA trial. J. Clin. Endocrinol. Metab. 98 (1), 322-329. doi:10.1210/jc.2012-2710

Lavine, J. E., Schwimmer, J. B., Van Natta, M. L., Molleston, J. P., Murray, K. F., Rosenthal, P., et al. (2011). Effect of vitamin E or metformin for treatment of nonalcoholic fatty liver disease in children and adolescents. JAMA 305 (16), 1659-1668. doi:10.1001/jama.2011.520

Love-Osborne, K., Sheeder, J., and Zeitler, P. (2008). Addition of metformin to a lifestyle modification program in adolescents with insulin resistance. J. Pediatr. 152 (6), 817-822. doi:10.1016/j.jpeds.2008.01.018

Mould, D. R. (2012). Model-based meta-analysis: an important tool for making quantitative decisions during drug development. Clin. Pharmacol. Ther. 92 (3), 283-286. doi:10.1038/clpt.2012.122

Nadeau, K. J., Chow, K., Alam, S., Lindquist, K., Campbell, S., McFann, K., et al. (2015). Effects of low dose metformin in adolescents with type I diabetes mellitus: a randomized, double-blinded placebo-controlled study. Pediatr. Diabetes 16 (3), 196-203. doi:10.1111/pedi.12140

Nadeau, K. J., Ehlers, L. B., Zeitler, P. S., and Love-Osborne, K. (2009). Treatment of non-alcoholic fatty liver disease with metformin versus lifestyle intervention in insulin-resistant adolescents. Pediatr. Diabetes 10 (1), 5-13. doi:10.1111/j. 1399-5448.2008.00450.x

Nwosu, B. U., Maranda, L., Cullen, K., Greenman, L., Fleshman, J., McShea, N., et al. (2015). A randomized, double-blind, placebo-controlled trial of adjunctive metformin therapy in overweight/obese youth with type 1 diabetes. PLoS One 10 (9), e0137525. doi:10.1371/journal.pone.0137525

Pastor-Villaescusa, B., Cañete, M. D., Caballero-Villarraso, J., Hoyos, R., Latorre, M., Vázquez-Cobela, R., et al. (2017). Metformin for obesity in prepubertal and pubertal children: a randomized controlled trial. Pediatrics 140 (1), e20164285. doi:10.1542/peds.2016-4285

Pu, R., Shi, D., Gan, T., Ren, X., Ba, Y., Huo, Y., et al. (2020). Effects of metformin in obesity treatment in different populations: a meta-analysis. Ther. Adv. Endocrinol. 11, 204201882092600. doi:10.1177/2042018820926000

van der Aa, M. P., Elst, M. A. J., van de Garde, E. M. W., van Mil, E. G. A. H., Knibbe, C. A. J., and van der Vorst, M. M. J. (2016). Long-term treatment with metformin in obese, insulin-resistant adolescents: results of a randomized double-blinded placebo-controlled trial. Nutr. Diabetes 6 (8), e228. doi:10. 1038/nutd.2016.37

Wilson, D. M., Abrams, S. H., Aye, T., Lee, P. D., Lenders, C., Lustig, R. H., et al. (2010). Metformin extended release treatment of adolescent obesity: a 48-week randomized, double-blind, placebo-controlled trial with 48-week follow-up. Arch. Pediatr. Adolesc. Med. 164 (2), 116-123. doi:10.1001/archpediatrics. 2009.264

Wu, J., Xu, L., Lv, Y., Dong, L., Zheng, Q., and Li, L. (2017). Quantitative analysis of efficacy and associated factors of calcium intake on bone mineral density in postmenopausal women. Osteoporos. Int. 28 (6), 2003-2010. doi:10.1007/ s00198-017-3993-4

Yanovski, J. A., Krakoff, J., Salaita, C. G., McDuffie, J. R., Kozlosky, M., Sebring, N. G., et al. (2011). Effects of metformin on body weight and body composition in obese insulin-resistant children: a randomized clinical trial. Diabetes 60 (2), 477-485. doi:10.2337/db10-1185

Yerevanian, A., and Soukas, A. A. (2019). Metformin: mechanisms in human obesity and weight loss. Curr. Obes. Rep. 8 (2), 156-164. doi:10.1007/s13679019-00335-3

Conflict of Interest: The authors declare that the research was conducted in the absence of any commercial or financial relationships that could be construed as a potential conflict of interest.

Copyright (c) 2021 Wang, Mao, He and Chen. This is an open-access article distributed under the terms of the Creative Commons Attribution License (CC $B Y)$. The use, distribution or reproduction in other forums is permitted, provided the original author(s) and the copyright owner(s) are credited and that the original publication in this journal is cited, in accordance with accepted academic practice. No use, distribution or reproduction is permitted which does not comply with these terms. 